\title{
STRUKTUR KOMUNITAS MANGROVE DI PESISIR DESA TATENGESAN, KECAMATAN POSOMAEN, KABUPATEN MINAHASA TENGGARA
}

\author{
(Structure of mangrove community on the coastal of Tetengesan, Posomaen District, \\ Southeast Minahasa Regency)
}
Maykel R. Munaimbala ${ }^{1}$, Carolus P. Paruntu², Antonius P. Rumengan², Calvin F.A Sondak ${ }^{2}$, Sandra Tilaar ${ }^{2}$, Joudy R.R Sangari ${ }^{3}$

1. Mahasiswa Program Studi Ilmu Kelautan, FPIK, UNSRAT Manado

2. Staf Pengajar Program Studi Ilmu Kelautan, FPIK, UNSRAT Manado

3. Staf Pengajar Program Studi Manajemen Sumberdaya Perairan, FPIK UNSRAT Manado

Penulis korespondensi: antonius rumengan@unsrat.ic.id

\begin{abstract}
Abstrak
Tujuan penelitian ini yaitu untuk mengkaji struktur komunitas mangrove di pesisir Tatengesan, Kecamatan Posomaen, Kabupaten Minahasa Tenggara, Sulawesi Utara. Pengambilan data struktur komunitas mangrove ini menggunakan metode line transek kuadrat yang berukuran $10 \mathrm{~m} \times 10 \mathrm{~m}$ sebanyak 5 kali. Waktu pelaksanaan penelitian selama 6 (enam) bulan tahun 2021, mulai dari penyusunan proposal, pengambilan data analisis, ujian hasil penelitian, dan dilaksanakannya ujian skripsi. Berdasarkan hasil penelitian, ditemukan 3 jenis mangrove yaitu: Rhizophora apiculata, Rhizophora mucronata, dan Bruguiera gymnorrhiza. Nilai dari kerapatan relatife jenis tertinggi terdapat pada transek 2 dengan nilai $88,33 \%$ oleh $R$. mucronata. Untuk nilai frekuensi relative jenis tertinggi pada transek 1,2 dan 3 oleh $R$. mucronata yaitu $8,3 \mathrm{~cm} / \mathrm{m}$. Penutupan relative jenis tertinggi dimiliki oleh $R$. mucronata dengan nilai $76,99 \%$ pada transek 2 . Indeks nilai penting tertinggi terdapat pada $R$. mucronata yaitu 220,88 pada transek 2 . Indeks keanekaragaman tertinggi terdapat pada transek 3 dengan nilai sebesar 0,85 . indeks kemerataan tertinggi terdapat pada transek 1 dengan nilai 0,99 . Penelitian selanjutnya perlu dilakukan inventarisasi jenis-jenis mangrove dengan metode jelajah untuk mengetahui keseluruhan jenis di lokasi penelitian.
\end{abstract}

Kata Kunci : Mangrove, Tatengesan, Komunitas, Keanekaragaman dan Kemerataan

\begin{abstract}
The purpose of this study was to examine the structure of the mangrove community on the coast of Tatengesan, Posomaen District, Southeast Minahasa Regency, North Sulawesi. The data collection of the mangrove community structure used the line transect quadratic method measuring 10 $\mathrm{m} \times 10 \mathrm{~m} 5$ times. The research implementation period is 6 (six) months in 2021, starting from the preparation of proposals, data analysis, examination of research results, and the implementation of thesis examinations. Based on the results of the study, found 3 types of mangroves, namely: Rhizophora apiculata, Rhizophora mucronata, and Bruguiera gymnorrhiza. The value of the highest species relative density was found on transect 2 with a value of $88.33 \%$ by $R$. mucronata. For the value of the highest relative frequency of species on transects 1,2 and 3 by $R$. mucronata, namely $8.3 \mathrm{~cm} / \mathrm{m}$. The highest relative species cover was $R$. mucronata with a value of $76.99 \%$ on transect 2 . The highest important value index was found in $R$. mucronata, which was 220.88 on transect 2 . The highest diversity index was found on transect 3 with a value of 0.85 . The highest evenness index was found on transect 1 with a value of 0.99 . For further research, it is necessary to conduct an inventory of mangrove species using the roaming method to find out all the species in the research location.
\end{abstract}

Keywords: Mangrove, Tatengesan, Community, Diversity and Evenness 


\section{PENDAHULUAN}

Indonesia merupakan negara yang memiliki mangrove terluas di dunia dan juga memiliki keragaman hayati yang terbesar serta strukturnya paling bervariasi (Noor, dkk. 2006). Mangrove adalah tumbuhan khas pesisir yang dipengaruhi oleh pasang surut air laut (Sukardjo 1984; Rumengan dkk 2018). Bengen (2001) mengemukakan bahwa mangrove merupakan komunitas vegetasi pantai tropis yang didomonasi oleh beberapa jenis mangrove yang dapat tumbuh dan berkembang di beberapa daerah pasang surut pantai berlumpur.

Fungsi mangrove yang terpenting bagi daerah pantai adalah menjadi penyambung darat dan laut. Tumbuhan, hewan, benda-benda lainnya dan nutrisi tumbuhan ditransfer ke arah darat atau ke arah laut melalui mangrove. Mangrove juga berperan sebagai filter untuk mengurangi efek yang merugikan dan perubahan lingkungan utama, dan sebagai sumber makanan bagi biota laut (pantai) dan biota darat (Syah, dkk. 2012).

Permasalahan yang masih terjadi sampai pada saat ini yaitu penebangan liar pohon mangrove, pencemaran dan pembangunan di kawasan pesisir yang mengakibatkan berkurangnya luasan kawasan hutan mangrove, khususnya di lokasi penelitian. Berkurangnya kawasan hutan mangrove memiliki dampak bukan hanya terhadap kawasan itu sendiri, tapi juga pada ekosistem terkait lainnya dan bagi manusia. Penelitian ini bertujuan untuk mengetahui struktur komunitas mangrove di pesisir Desa Tatengesan, Kecamatan Posomaen, Kabupaten Minahasa Tenggara, Sulawesi Utara.

\section{METODE PENELITIAN}

\section{Waktu dan Tempat}

Penelitian ini dilakukan di di pesisir Tatengesan, Kecamatan Posomaen, Kabupatan Minahasa Tenggara, pada tanggal 23 April 2021. Peta lokasi penelitian dapat dilihat pada (Gambar 1).



Gambar 1. Peta lokasi pengambilan data.

\section{Pengambilan Data}

Metode yang digunakan dalam penelitian ini adalah metode transek kuadrat. Teknik pengambilan data dilakukan dengan cara menarik garis lurus dari arah laut bagian vegetasi mangrove terluar ke arah darat. Bentangan transek garis sepanjang $100 \mathrm{~m}$ diletakkan di 3 transek dimana tiap transek terdapat 5 plot atau petak kuadrat berukuran $10 \times 10 \mathrm{~m}^{2}$ dengan jarak antar plot $10 \mathrm{~m}$. Adapun informasi pustaka tentang jenis mangrove untuk identifikasi menggunakan beberapa buku panduan mangrove (Noor, dkk. 2006).

\section{Analisa Data}

Data yang sudah ditemukan dianalisis secara deskriptif dan disajikan dalam bentuk tabel dan perhitungan matematik. Data mengenai spesies, jumlah individu, dan diameter pohon dengan menggunakan metode line transect kuadrat, diolah lebih lanjut untuk mebndapatkan nilai kerapatan spesies, frekuensi spesies, penutupan jenis, nilai penting, keanekaragaman spesies dam indeks kemerataan (Bengen 2002; Paruntu, dkk. 2017; Pandeirot, dkk 2020), sebagai berikut :

\section{Kerapatan jenis (Di)}

$\mathrm{Di}=\frac{\text { Jumlah total individu } \mathrm{ke}-\mathrm{i}}{\text { luas total area pengamatan }} \times 10.000$

Kriteria nilai indeks kerapatan berdasarkan Keputusan Menteri Lingkungan Hidup No. 201 tahun 2004 sebagai berikut : 


$$
\begin{array}{ll}
\geq 1500 & : \text { Padat } \\
1000-1500 & : \text { Sedang } \\
<1000 & : \text { Jarang }
\end{array}
$$

\section{Kerapatan relatif (RDi)}

$\mathrm{RDi}=\frac{\text { jumlah total individu ke-i }}{\text { total tegakan seluruh jenis }} \times 100$

\section{Frekuensi jenis (Fi)}

$\mathrm{Fi}=\frac{\text { jumlah petak ditemukan suatu jenis }}{\text { jumlah total petak yang dibuat }}$

\section{Frekuensi relatif $(\mathrm{RFi})$}

$\mathrm{RFi}=\frac{\text { jumlah petak ditemukan suatu jenis }}{\text { jumlah total petak yang dibuat }} \times 100$

\section{Penutupan jenis (Ci)}

$\mathrm{Ci}=\frac{\text { jumlah besar area DBH jenis }-\mathrm{i}}{\text { luas total area pengambilan contoh }} \times 10.000$

\section{Penutupan relatif $(\mathrm{RCi})$}

$\mathrm{RC} i=\frac{\text { tutupan jenis ke- } \mathrm{i}}{\text { tutupan total seluruh jenis }} \times 100$

Kriteria nilai indeks penutupan (\%) yaitu :

$$
\begin{array}{ll}
\geq 75 \% & : \text { Padat } \\
50 \%-75 \% & : \text { Sedang } \\
<50 \% & : \text { Jarang }
\end{array}
$$

\section{Indeks nilai penting (INP)}

$$
\mathrm{INP}=\mathrm{RDi}+\mathrm{RFi}+\mathrm{RCi}
$$

\section{Keanekaragaman $\left(\mathbf{H}^{\prime}\right)$}

$$
\mathrm{H}^{\prime}=-\sum_{i=1}^{s} \frac{n i}{N} \operatorname{In} \frac{n \mathrm{i}}{N}
$$

Keterangan :

$$
\begin{aligned}
& \mathrm{H}^{\prime}=\text { Indeks keanekaragaman } \\
& \mathrm{ni}=\text { Jumlah individu masing-masing } \\
& \mathrm{N}=\text { jenis } \\
& \text { Jumlah total individu semua jenis. }
\end{aligned}
$$

Menurut Wilhm dan Dorris (1968), kriteria indeks keanekaragaman dibagi dalam 3 kategori yaitu :

$$
\begin{array}{cc}
\mathrm{H}^{`}<1 & \begin{array}{c}
\text { : Keanekaragaman jeni } \\
\text { rendah }
\end{array} \\
1<\mathrm{H}^{`}<3: & \begin{array}{c}
\text { Keanekaragaman jenis } \\
\text { sedang }
\end{array} \\
\mathrm{H}^{\prime}>3 & \begin{array}{l}
\text { : Keanekaragaman jenis } \\
\text { tinggi. }
\end{array}
\end{array}
$$

\section{Indeks kemerataan (E)}

Indek kemerataan menggambarkan ukuran jumlah individu antar spesies dalam suatu komunitas. Indeks kemerataan jenis di hitung dengan menggunakan rumus Eveness Index (Magurran, 1988) yaitu :

Dimana :

$$
\mathrm{E}=\frac{H^{\prime}}{\operatorname{In} S}
$$

$$
\begin{aligned}
& E: \text { Kemerataan jenis } \\
& H^{\prime}: \text { Indeks keragaman } \\
& S: \text { Jumlah jenis. }
\end{aligned}
$$

Kriteria indeks kemerataan berkisar $0-1$, jika nilainya 0 menunjukan tingkat kemerataan spesies pada komunitas tersebut sangat tidak merata, sedangkan jika nilainya mendekati 1 maka hampir seluruh spesies yang ada memiliki kelimpahan yang sama (Magurran 1988).

\section{HASIL DAN PEMBAHASAN}

\section{Jenis-Jenis Mangrove}

Berdasarkan dengan hasil penelitian yang dilakukan di 3 stasiun ditemukan 3 jenis mangrove yaitu, Rhizophora apiculata, Rhizophora mucronata dan Bruguiera gymnorrhiza. Dari 3 jenis mangrove yang ditemukan, jenis $R$. mucronata adalah yang paling banyak ditemukan di lokasi penlitian.

\section{Kerapatan Jenis dan Kerapatan Relatif Jenis}

Hasil penelitian memperlihatkan bahwa transek 1 memiliki kerapatan jenis $R$. apiculata dan $R$. mucronata, masingmasing sebesar 540 dan 480 pohon/ha, dan selanjutnya nilai kerapatan relatif jenis masing-masing yaitu 52,94 dan $47,06 \%$. Transek 2 memiliki kerapatan jenis mangrove $R$. mucronata sebesar 1060 pohon/ha, $R$. apiculata sebesar 120 pohon/ha, dan B. gymnorrhiza sebesar 20 
pohon/ha, dan selanjutnya nilai kerapatan relatif jenisnya, masing-masing yaitu $88,33 \%, 10,00 \%$, dan 1,67\%. Transek 3 memiliki kerapatan jenis $R$. mucronata dengan nilai 560 pohon/ha, B. gymnorrhiza 340 pohon/ha dan $R$. apiculata 60 pohon/ha, selanjutnya kerapatan relatif jenisnya, masing-masing yaitu 58,33\%, $35,42 \%$ dan $6,25 \%$. Nilai kerapatan tertinggi di setiap transek pengamatan dimiliki oleh $R$. mucronata. Untuk nilai ratarata kerapatan jenis dan kerapatan relatif jenis dapat dilihat pada (Gambar 2 dan 3).

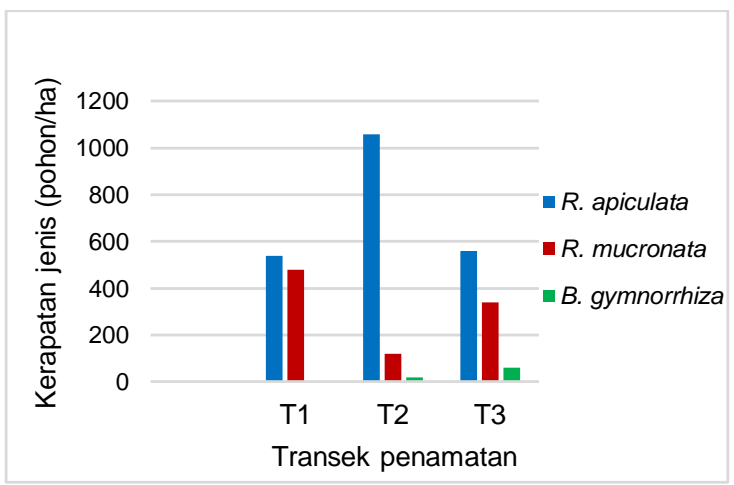

Gambar 2. Kerapatan jenis (pohon/ha) di setiap transek pengamatan.

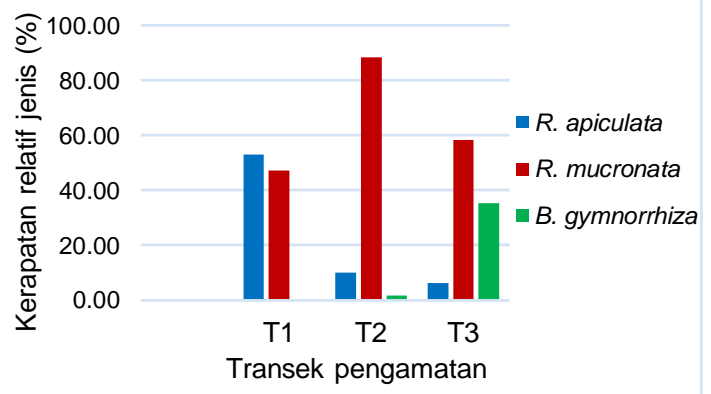

Gambar 3. Kerapatan relatif jenis di setiap transek pengamatan.

\section{Frekuensi Jenis dan Frekuensi Relatif Jenis}

Hasil penelitian memperlihatkan bahwa transek 1 memiliki frekuensi jenis $R$. apiculata dan $R$. mucronata adalah sama yaitu sebesar 1,00 dan selanjutnya nilai frekuensi relatif jenis yaitu sama $50,00 \%$; Transek 2 memiliki frekuensi jenis mangrove $R$. mucronata sebesar 1,00, $R$. apiculata sebesar 0,60 dan B. gymnorrhiza sebesar 0,20, dan selanjutnya nilai frekuensi relatif jenisnya, masing-masing yaitu $55,56 \%, \quad 33,33 \%$ dan $11,11 \%$. Transek 3 memiliki frekuensi jenis $R$. mucronata dengan nilai $1,00, B$. gymnorrhiza 0,80 dan $R$. apiculata 0,20, selanjutnya kerapatan relatif jenisnya, masing-masing yaitu $50,00 \%, 40,00 \%$ dan $10,00 \%$. Nilai frekuensi tertinggi di setiap transek pengamatan dimiliki oleh $R$. mucronata. Untuk nilai rata-rata kerapatan jenis dan kerapatan relatif jenis dapat dilihat pada (Gambar 4 dan 5).

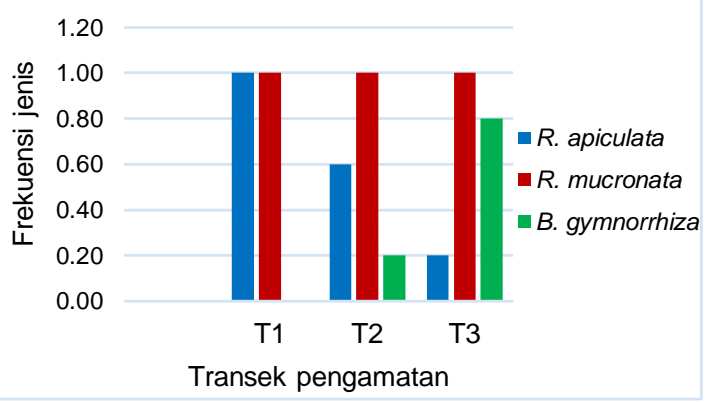

Gambar 4. Frekuensi jenis di setiap transek pengamatan.

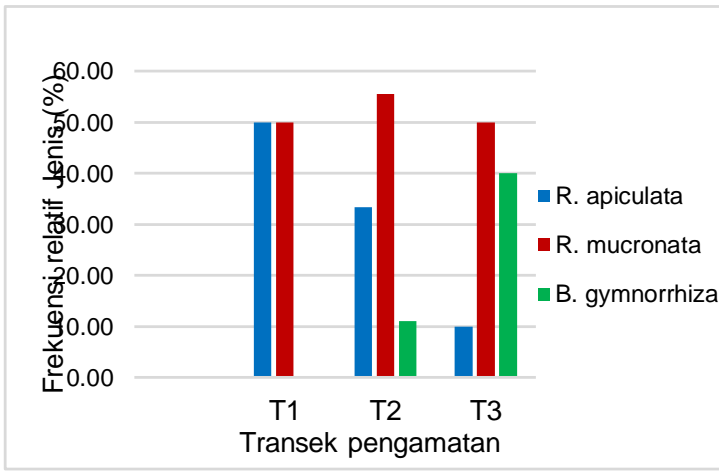

Gambar 5. Frekuensi relatif jenis di setiap transek pengamatan.

\section{Penutupan Jenis dan Penutupan Relatif Jenis}

Hasil penelitian memperlihatkan bahwa transek 1 memiliki penutupan jenis $R$. apiculata dan $R$. mucronata, masingmasing sebesar 5,90 dan $5,28 \mathrm{~cm} / \mathrm{m}$, dan selanjutnya nilai penutupan relatif jenisnya, masing-masing yaitu $52,79 \%$ dan $47,21 \%$; Transek 2 memiliki penutupan jenis mangrove $R$. mucronata sebesar 8,35 $\mathrm{cm} / \mathrm{m}, B$. gymnorrhiza sebesar $1,53 \mathrm{~cm} / \mathrm{m}$, dan $R$. apiculata sebesar $0,96 \mathrm{~cm} / \mathrm{m}$, dan selanjutnya nilai penutupan relatif jenisnya, masing-masing yaitu $76,99 \%, 14,11 \%$ dan 
$8,9 \%$. Transek 3 memiliki penutupan jenis R. mucronata dengan nilai $4,33 \mathrm{~cm} / \mathrm{m}, B$. gymnorrhiza $4,11 \mathrm{~m}^{2} /$ ha dan $R$. apiculata $1,16 \mathrm{~cm} / \mathrm{m}$, selanjutnya penutupan relatif jenisnya, masing-masing yaitu $45,14 \%$, $42,81 \%$ dan $12,05 \%$. Nilai penutupan jenis tertinggi di setiap transek pengamatan dimiliki oleh $R$. mucronata. Untuk nilai ratarata penutupan jenis dan penutupan relatif jenis dapat dilihat pada (Gambar 6 dan 7).
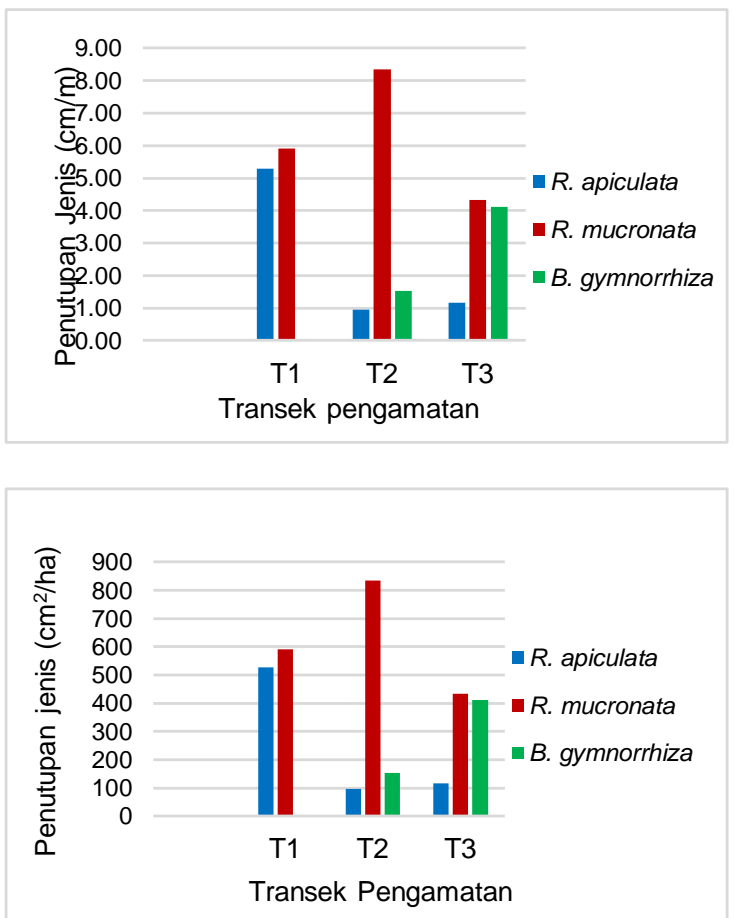

Gambar 6. Penutupan jenis $(\mathrm{cm} / \mathrm{m})$ di setiap transek pengamatan.

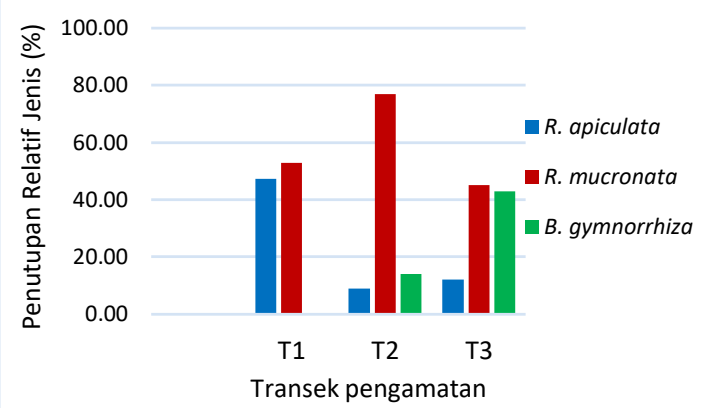

Gambar 7. Penutupan relatif jenis di setiap transek pengamatan.

\section{Indeks Nilai Penting}

Hasil penelitian sekarang ini memperlihatkan bahwa transek 1 memiliki indeks nilai penting $R$. apiculata dan $R$. mucronata, masing-masing sebesar $150,15 \%$ dan $149,85 \%$. Transek 2 memiliki indeks nilai penting $R$. mucronata sebesar 220,88 \%, R. apiculata 52,24\%, dan B. gymnorrhiza sebesar 26,89\%. Transek 3 memiliki indeks nilai penting $R$. mucronata dengan nilai $153,48 \%, B$. gymnorrhiza 118,23\%, dan $R$. apiculata $28,3 \%$. Indeks nilai penting tertinggi di keseluruhan transek pengamatan dimiliki oleh R. mucronata. Untuk nilai rata-rata indeks nilai penting dapat dilihat pada (Gambar 8).

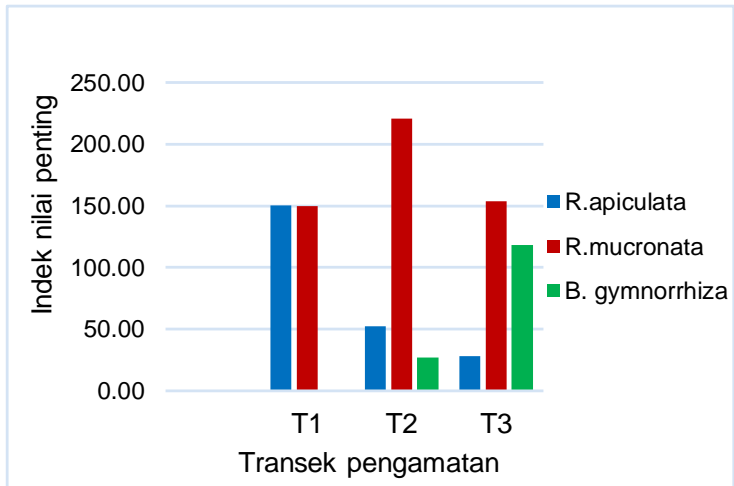

Gambar 8. Indeks nilai penting di setiap transek pengamatan.

\section{Indeks Keanekaragaman $\left(\mathrm{H}^{\prime}\right)$}

Hasil penelitian memperlihatkan bahwa transek 1 memiliki nilai indeks keanekaragaman sebesar 0,69, transek 2 memiliki nilai indeks keanekaragaman sebesar 0,40, transek 3 memiliki nilai indeks keanekaragaman sebesar 0,85 . Nilai indeks keanekaragaman tertinggi di keseluruhan transek pengamatan dimiliki oleh transek 3, dan ini dapat dilihat pada (Gambr 9).

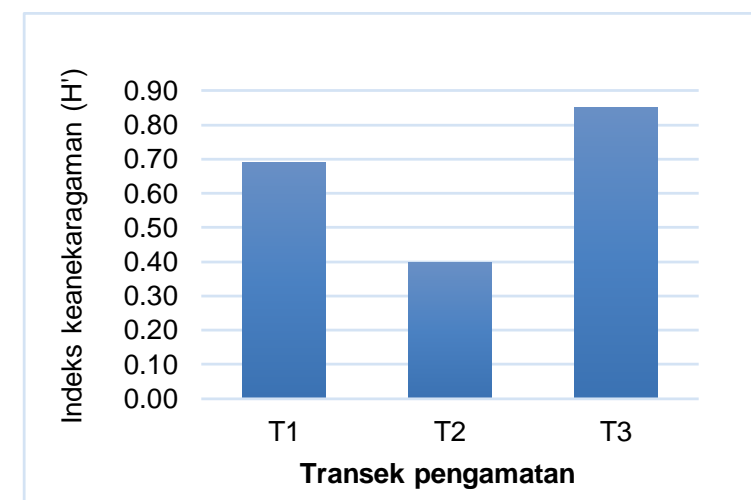

Gambar 9. Indeks Keanekaragaman di setiap transek pengamatan. 


\section{Indeks Kemerataan (E)}

Hasil penelitian sekarang ini memperlihatkan bahwa transek 1 memiliki nilai indeks kemerataan sebesar 0,99, transek 2 memiliki nilai indeks kemerataan sebesar 0,25, transek 3 memiliki nilai indeks kemerataan sebesar 0,53. Nilai indeks kemerataan tertinggi di antara 3 (tiga) transek pengamatan ditemukan pada transek 1, dan ini dapat dilihat pada (Gambar 10). Nilai indeks kemerataan pada setiap transek penelitian berkisar antara 0,25 -0,99. Berdasarkan kriteria, nilai tersebut tergolong tinggi pada transek 1, kemudian diikuti transek 2 dengan kriteria sedang dan pada transek 3 dengan kategori rendah.



Gambar 10. Indeks kemerataan jenis di setiap transek pengamatan.

\section{KESIMPULAN}

1) Jenis-jenis mangrove yang ditemukan di lokasi penelitian di pesisir sekitar Desa Tatengesan, yaitu $R$. mucronata, $R$. apiculata dan $B$. gymnorrhiza yang termasuk dalam family Rhizophoraceae.

2) Nilai indeks penting tertinggi ditemukan pada jenis $R$. mucronata, sedangkan yang terendah ditemukan pada jenis $B$. gymnorrhiza.

3) Nilai indeks keanekaragaman $\left(\mathrm{H}^{\prime}\right)$ dikategorikan rendah dan nilai indeks kemerataan dikategorikan sedang.

\section{DAFTAR PUSTAKA}

Bengen, D.G. 2001. Ekosistem Dan Sumber Daya Pesisir Dan Laut Serta Pengelolaan Secara Terpadu Dan Berkelanjutan. Prosiding Pelatihan Pengelolaan Wilayah Pesisir Terpadu. hal. 2855.

Bengen, D.G. 2002. Pengenalan dan Pengelolaan Ekosistem Mangrove. Pusat Kajian Sumberdaya Pesisir dan Lautan. Fakultas Perikanan dan IImu Kelautan. Institut Pertanian Bogor. Jakarta. 56 hal.

Keputusan Menteri Lingkungan Hidup Republik Indonesia No. 201 tahun 2004 tentang Kriteria Baku dan Pedoman Penentuan Kerusakan Mangrove.

Magurran, A.E. 1988. Ecological Diversity and Its Measurement. Princeton University Press.

Noor, Yus Rusila, M. Khazali, dan I N.N. Suryadiputra. 2006. Panduan Pengenalan Mangrove Di Indonesia.

Pandeirot, G.L., A.P Rumengan., C.P. Paruntu., S. Darwisito., M. Ompi dan A.S. Wantasen. 2020. Analisis Struktur Komunitas Mangrove Di Kawasan Sekitar Pt. Conch Kabupaten Bolaang Mongondow. Jurnal Pesisir Dan Laut Tropis, 8(2): hal 104-113.

Paruntu, C.P., A.B. Windarto dan A.P. Rumengan. 2017. Karakteristik Komunitas Mangrove Desa Motandoi Kecamatan Pinolosian Timur Kabupaten Bolaang Mongondow Selatan Provinsi Sulawesi Utara. Jurnal Pesisir dan Laut Tropis, 5(2): hal. 53-65.

Rumengan, A.P., D.M. Mantiri., R. Rompas., A. Hutahaean., T.L. Kepel., C.P. Paruntu dan G.S. Gerung. 2018. Carbon Stock Assessment of Mangrove Ecosystem in Totok Bay, Southeast Minahasa Regency, North Sulawesi, Indonesia. Aquaculture, 
Aquarium, Conservation \& Legislation, 11(4): hal. 12801288.

Syah, C., A. Indrawan dan A. Priyono. 2012. Pertumbuhan Rhizophora Mucronata Pada Lahan Restorasi Mangrove Di Hutan Lindung Angke Kapuk, Jakarta. Bonorowo Wetlands 2(1): hal. 1-10.

Wilhm, J. L dan T. C. Dorris. 1968. Biological Parameters for Water Quality Criteria. Bio Scientific Publication. London. 18: hal. 477481. 